\title{
FLUOROMETRIC DETERMINATION OF 5-HYDROXYINDOLE DERIVATIVES BY HIGH PERFORMANCE LIQUID CHROMATOGRAPHY WITH COBALT(II) CHLORIDE, SODIUM CARBONATE, AND SODIUM HYDROXIDE

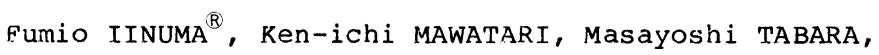 and Mitsuo WATANABE
}

Faculty of Pharmaceutical Sciences, Teikyo University Sagamiko-machi, Tsukui-gun, Kanagawa 199-01, Japan

High-performance 1 iquid chromatoghraphic determination of 5-hydroxyindole derivatives was established. The postcolumn derivatization with sodium carbonate-sodium hydroxide-cobalt(II) chloride reagent allowed the determination of pmol level of the substances. This technique was applied to the determination of 5-hydroxyindoleacetic acid in human urine.

The importance of the neuroregulatory and hormone action of serotonin has become well established ${ }^{1)}$. Although the biochemical pathway for central and peripheral metabolism of serotonin has been elucidated, the dynamics with respect to normal and stressed conditions are being investigated. Recently, high peformance liquid chromatography (HPLC) methodologies have provided a rapid and simultaneous determination of several indole compounds. The combination of HPLC with flow through fluorometric detection of 5-hydroxyindoles ${ }^{2) 3}$ ) seems to give significant improvement of sensitivity. Native fluorescence of 5-hydroxyindoles and fluorescence reaction with o-phthalaldehyde have been used for this purpose. However, these fluorescences are not specific to 5-hydroxyindoles, and we are prompted to develop more specific reaction.

Recently, we have developed a method for the fluorometric determination of tryptophan and its metabolite in serum based on the fact that these compounds gave fluorescence on reaction with hydrogen peroxide in alkaline solution ${ }^{4}$. But 5-hydroxyindoles such as serotonin and 5-hydroxyindoleacetic acid (5-HIAA) give no fluorescence on the reaction with hydrogen peroxide. In the present study, 5-hydroxyindoles were found to give fluoresce on heating under alkaline conditions. This reaction was applied to the HPLC determination of 5-hydroxyindoles in human urines.

\section{EXPER IMENTAL}

5-Hydroxyindoles and Lichrosorb RP-8 (5 $\mu \mathrm{m})$ were purchased from Sigma Chemical (St. Louis, MO, J.S.A.)., and E. Merck (Darmstadt, G.F.R.), respectivley. Other chemicals used were obtained from wako Pure Chemical (Osaka, Japan). 
Pretreatment of human urine ${ }^{51}$

Human urine was collected for $24 \mathrm{~h}$. To $1 / 100$ volume of the collected urine was added $0.85 \mathrm{ml}$ of perchloric acid and the mixture was made up to $25 \mathrm{ml}$ with distilled water. An aliquot $(2 \mathrm{ml})$ of the diluted sample solution was applied on a column of sephadex G-10 (3 cm x l cm I.D.). The column was washed with $20 \mathrm{ml}$ of $0.01 \mathrm{M}$ hydrochloric acid and then 5-HIAA was eluted with $10 \mathrm{ml}$ of $0.05 \mathrm{M}$ phosphate buffer (pH 7.7). The effluent was submitted to both the manual and chromatographic determination described below.

Manual procedure for the determination of 5 -hydroxyindoles

To $0.5 \mathrm{ml}$ of sample solution was added $2.5 \mathrm{ml}$ of aqueous $0.15 \mathrm{mM}$ sodium carbonate$0.12 \mathrm{M}$ sodium hydroxide-12 $\mu \mathrm{M}$ cobalt(II) chloride solution. The reagent solution was prepared just before used. The test tube was incubated in a water bath for 30 min at $80^{\circ} \mathrm{C}$. After cooling the tube in running water, the fluorescence intensity of the mixture was measured at $460 \mathrm{~nm}$ with excitation at $360 \mathrm{~nm}$ with a Hitachi Fluorescence spectrophotometer Model 650-10S.

HPLC of 5-hydroxyindoles

Figure 1 shows a schematic diagram of this system. The separation was

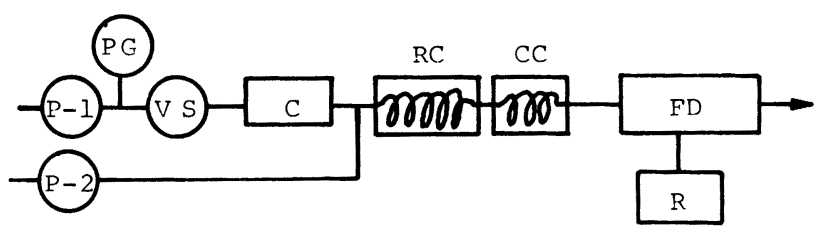

Fig. 1 Flow diagram of HPLC system for 5-hydroxyindoles using sodium carbonatesodium hydroxide-cobalt(II) chloride as postcolumn reagent

$\mathrm{P}-1$ : high pressure pump (flow rate, $0.75 \mathrm{ml} / \mathrm{min}$ ); $\mathrm{PG}$ : pressure gauge; VS: valve universal injector; C: LiChrosorb RP-8 column $(50 \mathrm{~mm} \times 4 \mathrm{~mm}$ I.D., particle size 5 $\mu \mathrm{m}) ; \mathrm{RC}$ : reaction coil ( $15 \mathrm{~m} \times 0.5 \mathrm{~mm} \mathrm{~J} . \mathrm{D} .$, stainless steel) maintained at $180^{\circ} \mathrm{C}$ in a silicon oil bath; CC: cooling coil (70 cm $\times 0.5 \mathrm{~mm}$ I.D., stainless steel); FD: fluorescence detector; $\mathrm{P}-2$ : reagent pump (flow rate, $0.5 \mathrm{ml} / \mathrm{min}$ ); R: recorder.

achieved on a reversed phase column (50 $\mathrm{mm} \times 4 \mathrm{~mm}$ I.D.), which was packed with LiChrosorb RP-8 (particle size $5 \mu \mathrm{m}$ ) by slurry packing method ${ }^{6}$ ) using SNk High Performance Column Packer Model SPC-102 (Sanuki Kogyo Tokyo, Japan). The mobile phase is $50 \mathrm{mM}$ acetate buffer ( $\mathrm{pH}$ 4.4) containing $0.1 \mathrm{M}$ sodiun sulfate and $0.5 \mu \mathrm{M}$ cobalt(II) chloride. A pressure pump with a valve universal injector (Sanuki Kogyo, Tokyo, Japan) is used to deliver nobile phase at a flow rate of 0.75 $\mathrm{ml} / \mathrm{min}$. The eluate was mixed with $0.5 \mathrm{M}$ sodium carbonate-2 $\mathrm{M}$ sodiun hydroxide in the reaction coil at $180 \pm 3^{\circ} \mathrm{C}$ to or fluorescent derivatives of 5 -hydroxyindoles. The temperature of the silicon oil bath was naintained at $180 \pm 3^{\circ} \mathrm{C}$ with a mantle 
heater. The fluorescence was monitored at $460 \mathrm{~nm}$ with excitation at $360 \mathrm{~nm}$ with a Hitachi Model 650-10S fluorescence spectrophotometer with a $40 \mu \mathrm{flow}$ cell.

\section{RESULTS AND DISCUSION}

Figure 2 shows excitation and emission spectra of serotonin reacted with the sodium carbonate-sodium hydroxide-cobalt(II) chloride reagent. Maxima of excitation were at 260, 315, and $360 \mathrm{~nm}$, and maximum of emission was at $460 \mathrm{~nm}$. The fluorescence intensity at $460 \mathrm{~nm}$ was enhanced in the presence of sodium hydroxide. Assuming that the relative fluorescence intensity was 100 when the reagent containing $0.1 \mathrm{M}$ sodium carbonate, $0.1 \mathrm{M}$ sodium hydroxide and $10 \mu \mathrm{M}$ cobalt(II) chloride was used, it decreased to 56 in the absence of sodium

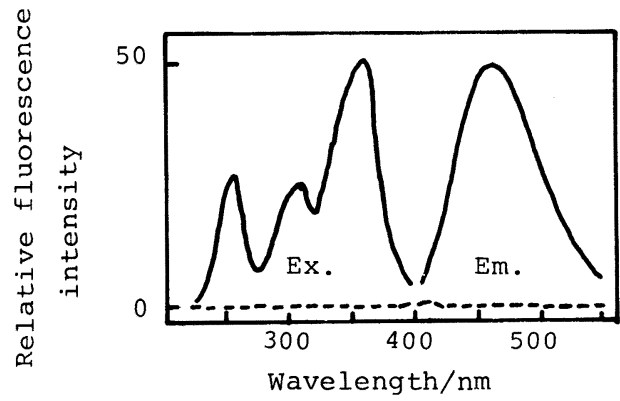

Fig. 2 Fluorescence excitation and emission spectra of serotonin allowed to react with sodium carbonate-sodium hydroxide-cobalt(II) chloride reagent

Table 1 Effect of addition of $10 \mu \mathrm{m}$ metal ion on the fluorescence intensity of serotonin (2.35 nmol)

\begin{tabular}{lc}
\hline Compound & $\begin{array}{c}\text { Relative fluorescence } \\
\text { intensity* }\end{array}$ \\
\hline None & 48.5 \\
Cobalt(II) chloride & 100 \\
Copper(II) sulfate & 47.6 \\
Magnesium(II) chloride & 22.6 \\
Manganese(II) acetate & 46.5 \\
Aluminium(II) chloride & 42.2 \\
Zinc(II) chloride & 28.3 \\
\hline
\end{tabular}

* Measured at $460 \mathrm{~nm}$ with excitation at $360 \mathrm{~nm}$.

Intensity for cobalt(II) chloride was taken as 100 . 
hydroxide. Table 1 shows the effect of the addition of metal ion on the fluorescence intensity of serotonin. Addition of cobalt(II) chloride markedly increased the fluorescence intensity, whereas other metal ions did not. Figure 3 shows the fluorescence intensity of serotonin relative to the concentration of cobalt(II) chloride. A plateau was observed between 10 and $100 \mu \mathrm{M}$ of cobalt(II) chloride.

Figure 4 shows the fluorescence intesity of serotonin as a function of reaction time at various reaction temperatures. The fluorescence intensity reached to a plateau after $20 \mathrm{~min}$ when reacted at $80^{\circ} \mathrm{C}$. Accordingly, the reaction time of $30 \mathrm{~min}$ was adopted in the manual procedure.

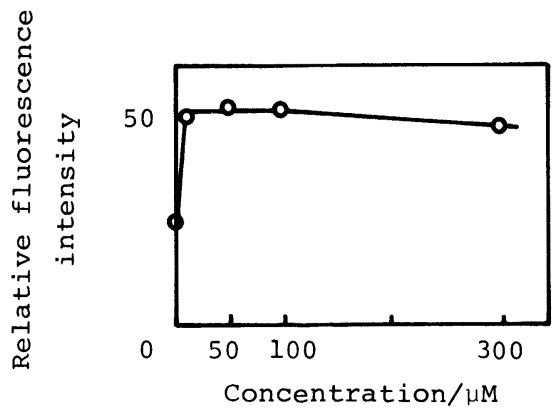

Fig. 3 Effect of concentration of cobalt (II) chloride on the fluorescence intensity of serotonin

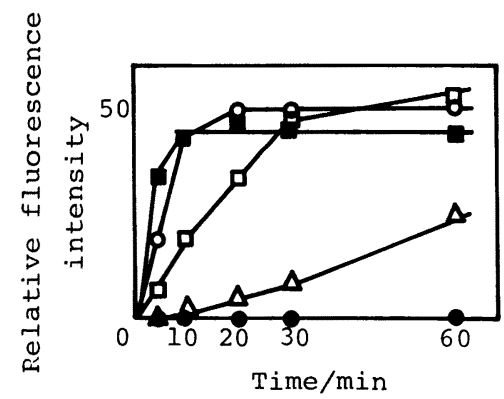

Fig. 4 Effects of reaction time and temperature on the fluorescence intensity of serotonin

- $20^{\circ} \mathrm{C} ;-\Delta: 50^{\circ} \mathrm{C} ;-\square: 70^{\circ} \mathrm{C} ;$ - -80 ${ }^{\circ} \mathrm{C} ;-$ : in a boiling water bath. Measured at $460 \mathrm{~nm}$ with excitation at $360 \mathrm{~nm}$.

The calibration curves for $\mathrm{N}$-acetylserotonin $(y=-0.43+98.5 x, r=1.000)$, 5-HIAA $(y=-1.75+85.1 x, r=0.998)$, and 5-hydroxytryptophol $(y=3.14+62.9 x, r=0.999)$ were linear in the range of final concentration of 30 pmol to 5.5 nmol. Those for serotonin $(y=-0.64+51.9 x, r=1.000), 5$-hydroxyindoleacetamide $(y=-0.12+9.0 x$, $r=1.000)$, and 5-hydroxytryptophan $(y=-0.48+7.3 x, r=0.996)$ were 1 inear in the range of 120 pmol to $5.5 \mathrm{nmol}, 260 \mathrm{pmol}$ to $6.3 \mathrm{nmol}, 225 \mathrm{pmol}$ to $5.5 \mathrm{nmol}$, respectively. The relative standard deviations of these compounds $(0,8$ nmol, $n=8)$ were less than 3 \%.

Relative fluorescence intensities of serotonin in the presence of various compounds are $\mathrm{l}$ isted in Table 2. Ascorbic acid and sodium sulfite did not interfere with the reaction of serotonin when the same amount was added to the sample. However, further addition of these compounds caused some interference. sucrose, ammonium sulfate, and amino acids affected the reaction slightly. Glucose and fructose were found to affect the assay. Sodium sulfate, creatine, 
creatinine, mannitol, and sorbitol did not interfere with the reaction.

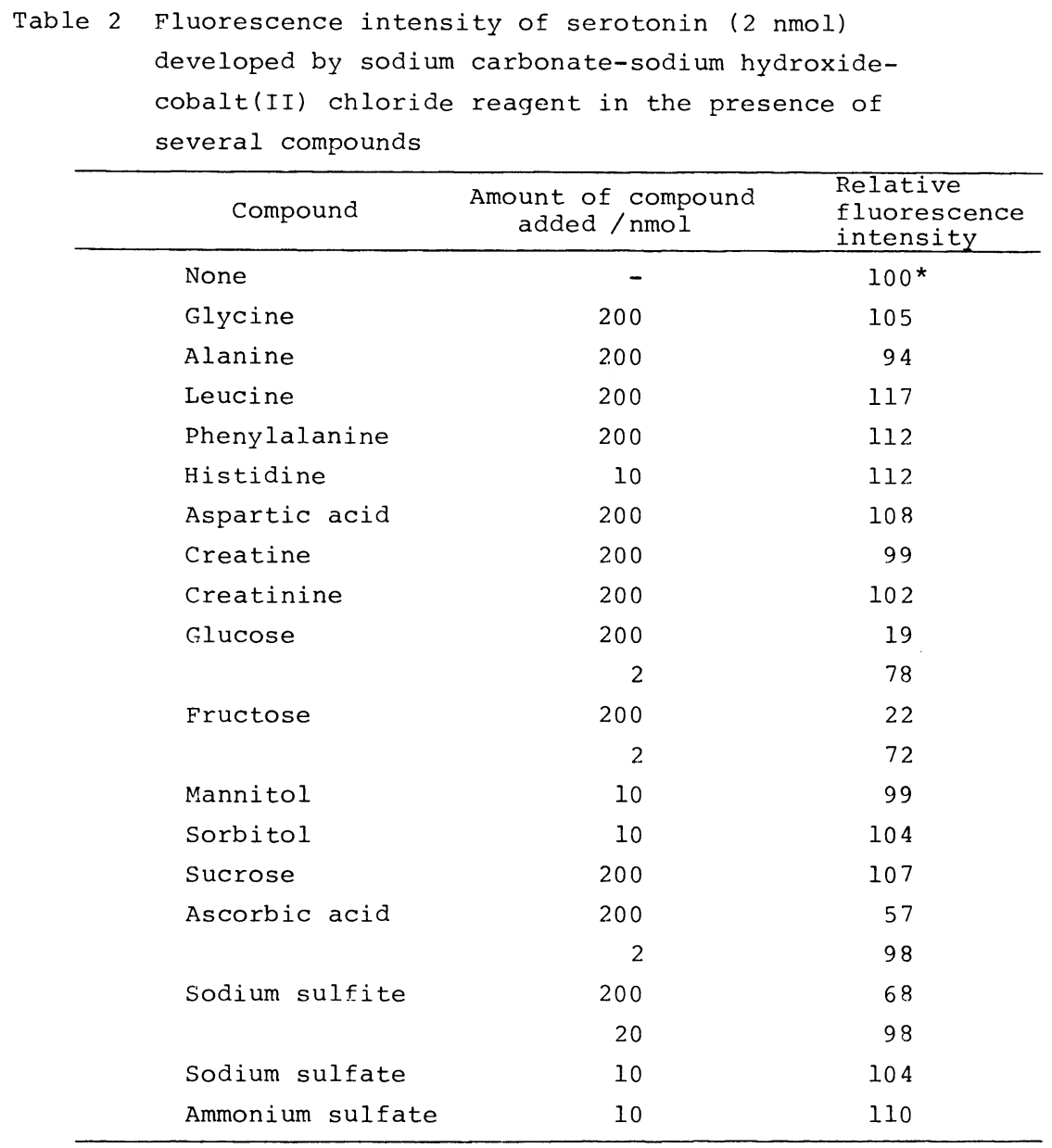

*Intensity on this condition was taken as 100 .

The above mentioned reaction was applied to the postcolumn derivatization of 5-hydroxyindoles in HPLC (Fig. 1). Elution with $50 \mathrm{mM}$ acetate buffer containing sodium sulfate $(\mathrm{pH} 5.3)$ Eacilitated the separation of 5-hydroxytryptophan (capacity ratio k': 0.94), 5-HIAA(k': 3.69), 5-hydroxytryptophol(k': 6.66), and Nacetylserotonin(k': 18.33), but serotonin overlapped with 5-HIAA. When the pH of the mobile phase was lowered to 4.4, 5-hydroxytryptophan( $\left.k^{\prime}: 0.94\right)$, serotonin( $k^{\prime}$ : 2.91), 5-HIAA ( $\left.k^{\prime}: 4.42\right)$, and 5-hydroxytryptophol( $k^{\prime}: 6.64$ ) could be separated, but $\mathrm{N}$-acetylserotonin was too strongly retained to elute from column. In the study described below, the mobile phase of pi 4.4 was used, because the analysis of 5-HIAA was nain purpose of the present investigation. Postcolumn derivatization was carried out by mixing the alkaline solution to the eluate from separa- 
Table 3 Effect of reaction condition of postcolumn derivatization for HPLC on the fluorescence intensity of 5-HIAA (50 pmol)

\begin{tabular}{lc}
\hline Reaction condition & $\begin{array}{c}\text { Relative fluorescence } \\
\text { intensity* }\end{array}$ \\
\hline $0.1 \mathrm{M} \mathrm{Na}_{2} \mathrm{CO}_{3}+0.8 \mathrm{M} \mathrm{NaOH}+15 \mu \mathrm{M} \mathrm{CoCl}_{2}$ & $100 * *$ \\
$0.1 \mathrm{M} \mathrm{Na}{ }_{2} \mathrm{CO}_{3}+0.8 \mathrm{M} \mathrm{NaOH}$ & 83 \\
$0.8 \mathrm{M} \mathrm{NaOH}+15 \mu \mathrm{M} \mathrm{CoCl}$ & 70 \\
$0.8 \mathrm{M} \mathrm{NaOH}$ & 22 \\
$0.1 \mathrm{M} \mathrm{Na}_{2} \mathrm{CO}_{3}+0.8 \mathrm{M} \mathrm{NaOH}+30 \mu \mathrm{M} \mathrm{CoCl}_{2}$ & 101
\end{tabular}

* Conditions of postcolumn derivatization were described in the Experimental. ** Intensity on this condition is taken as 100.

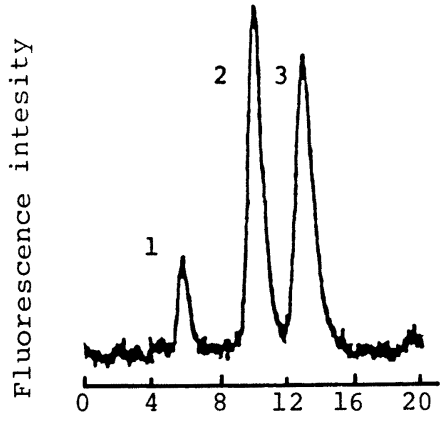

Retention time/min

Fig. 5 Chromatogram of 5-hydroxyindoles obtained by HPLC with postcolumn derivatization using sodium carbonate-sodium hydroxide-cobalt(II) chloride

Column: LiChrosorb RP-8 $(50 \mathrm{~mm} \times 4 \mathrm{~mm}$ I.D., particle size $5 \mu \mathrm{m})$; Mobile phase: $50 \mathrm{mM}$ acetate buffer ( $\mathrm{pH} 4.4$ ) containing $0.1 \mathrm{M}$ sodium sulfate and $0.5 \mu \mathrm{M}$ cobalt (II) chloride (flow rate, $0.5 \mathrm{ml} / \mathrm{min}$ ). Fluorescence intensity was monitored at $460 \mathrm{~nm}$ with excitation at $360 \mathrm{~nm}$. Peaks: 1; 45 pmol of 5-hydroxytryptophan, 2; 52 pmol of 5-HIAA, 3; 56 pmol of 5-hydroxytryptophol.

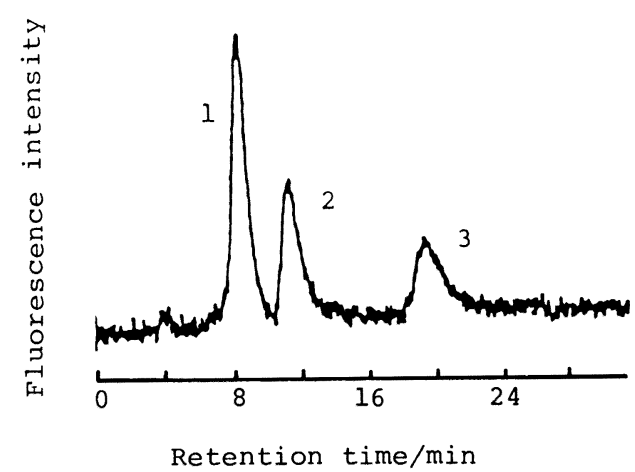

Fig. 6 Typical Chromatogram of 5-hydroxyindoles in urine

Urinary sample was pretreated with Sephadex G-10. HPLC conditions are the same as in Fig. 4. Peaks: 1;5-HIAA, 2 and 3 ; unknown. 
tion column at $180^{\circ} \mathrm{C}$. Table 3 shows the relative fluorescence intensity under various reaction conditions. Reaction temperature of $180^{\circ} \mathrm{C}$ gave high sensitivity. Figure 5 shows a chromatogram for the mixture of 5 -hydroxyindoles. Limits of detection of 5-hydroxytryptophan, 5-HIAA, and 5-hydroxytryptophol were 12 pmol, 5 pmol, 5 pmol, respectively. Standard 5-HIAA was detected as a single peak, with retention time of about $8 \mathrm{~min}$. The calibration curves for 5 -hydroxytryptophan $(y=-2.48+1.52 x, r=0.989), 5$-HIAA $(y=-10.6+5.78 x, r=0.999)$, and 5-hydroxytryptophol $(y=-9.18+4.96 x, r=0.993)$ were 1 inear in the range of 45 pmol to 900 pmol, 15 pmol to $100 \mathrm{pmol}, 15 \mathrm{pmol}$ to $100 \mathrm{pmol}$, respectively. The relative standard deviation for 105 pmol of 5-HIAA was $2.68(n=3)$. Figure 6 illustrates typical chromatogram of urine sample. The urinary sample gave the peak of 5-HIAAtogether with those of and two unknown substances. These unknown substances were clearly separated from 5-HIAA and its derivatives.

\begin{tabular}{lccccc} 
Table 4 & $\begin{array}{c}5 \text {-HIAA content in a urine sample and the recovery } \\
\text { of } 5 \text {-HIAA }\end{array}$ \\
\hline Method & $\begin{array}{c}\text { Endogeneous } \\
5 \text {-HIAA/ } \\
(\mu \mathrm{g} / \mathrm{ml})\end{array}$ & \begin{tabular}{c} 
Recovery test of \\
\cline { 3 - 5 }
\end{tabular} & $\begin{array}{c}\text { Added } / \text { HIAA } \\
\mu g\end{array}$ & $\begin{array}{c}\text { Found/ } \\
\mu g\end{array}$ & $\begin{array}{c}\text { Recovery } \\
(8)\end{array}$ \\
\hline Manual & 1.87 & 3.00 & 3.00 & 100 \\
HPLC & 1.55 & 3.00 & 3.06 & 102
\end{tabular}

Urine sample was collected for $24 \mathrm{~h}$. Total volume of urine sample was $2450 \mathrm{ml}$.

Table 4 shows 5-HIAA content in a urine sample and recovery of 5-HIAA from the sample by manual and HPLC method. Excellent recoveries were observed for both manual and HPLC method. Content of 5-HIAA in urine measured by HPLC method was lower than that by the manual method. This might suggest that substances other than 5-HIAA interfere with the manual method and these substances can be eliminated by the HPLC method.

\section{REFERENCES}

1) M.D. Gershon: "Handbook of Physiology", Chap. 16 (1977),(Nilliams and Wilkins, Baltimore).

2) T. Hojo, H. Nakanura, Z. Tamura: Chem. Pharm. Bull., 30, 189 (1982).

3) G. Anderson, w.C. Purdy: Anal. Chem., 51, 283 (1979).

4) F. Iinuma, K. Mawatari, M. Tabara, M. Watanabe: J. Pharm. Dym., 7, s-10 (1984).

5) T. Karasawa, M. Shimizu: Life Sci., 15, 1465 (1974).

6) Y. Yamauchi, J. Kumanotani: T. Chromatogr., 210, 512 (1981). 


\section{Keyword pharases}

fluorometric determination of 5-hydroxyindole derivatives in urine by high performance liquid chromatography ; determination of urinary 5-hydroxyindoletacetic acid; postcolumn derivatzation with sodiun carbonate-sodium hydroxide-cobalt (II) chloride. 